\title{
ON THE ANATOMY OF SOME AGNATHOUS MOLLUSCS FROM NEW ZEALAND.
}

\author{
By R. Мurdoch.
}

Read 9th November, 1900.

\section{PLATE XVII.}

\section{Rhytida Greenwood, Gray. Pl. XVII, Figs. 5 and 6.}

Animal very dark grey in colour, the neck, tail, and sides of body with small, irregularly shaped, flattish granules, which form irregular rows and extend to the foot-margin; tail flattened and pointed, it has a well-marked shallow median groove, but no mucous pore. Foot-sole thrown into transverse wrinkles; sides dark ash-grey, and centre lighter. Labial tentacles small, somewhat triangular in outline. The above description is from specimens preserved in spirits. Suter has given a figure of the animal taken from life (Journ. Malac., vol. vii, 1889, pl. iii, fig. 1).

The mantle projects slightly over the margin of the shell; on its under side are developed three small lobes (Pl. XVII, Fig. 5); that on the left (l.l.) is very small and narrow, with a small portion of each end free; the right lobe (r.l.) extends almost to the edge of the mantle, its left edge resting on the sub-central lobe (s.c.l.); this last and largest lobe is hatchet-shaped, somewhat fleshy, and projects beyond the mantle edge; from its base a shallow groove proceeds to the left, passing under the left lobe.

On opening the body-cavity, the most noticeable feature is the enormous size and muscular development of the buccal mass; all other organs seem dwarfed by comparison. The posterior end of the mass is drawn down and forward by a powerful ventral muscle; this muscle is very compact where it leaves the curved end of the mass; passing forward it spreads out, and largely forms the ventral portion of the outer muscular sheath. Beneath this sheath is the constrictor muscle, which forms a strong wrapper, the fibres transverse to those above; both muscles are intimately connected by a network of delicate fibres. It appears that the large ventral muscle materially assists in the protrusion of the radula; the contraction of the muscle would have the effect of shortening, or pulling the ends of the mass towards each other, this would compress the transverse fibres of the constrictor muscle, and the contraction of the latter would further assist in the expulsion of the radula. The muscular bands attached to the radular membrane, so far as I could separate them, appear similar to, though less strongly developed than, those in Natalina Caffra, Fér., of which Mr. M. F. Woodward has given an excellent description (Proc. Malac. Soc. Lond., Vol. i, pp. 270-277, Pl. xvii). The retractor muscle 
unites with the buccal mass in the form of a hollow cone, applied to all sides of the posterior end. The œsophagus opens into the buccal cavity in the anterior third of the mass, and so do the two salivary ducts; the salivary glands partly envelop the œsophagus, the inner edges of each gland are pressed together, giving the appearance of a single median gland, they are readily separated, and each seems functionally distinct. The other portion of the alimentary canal closely resembles that of Helix. The dentition has been described and figured by Hutton (Trans. New Zeal. Inst., vol. xvi, p. 167, pl. x, fig. P); Moss, too, gives a good figure of the teeth of a half-grown specimen, possessing a central tooth, and describes a radula having an abnormal formula (Trans. Manchester Micro. Soc., 1894, pl. ii, fig. 3). An examination of the teeth of four specimens gave the following result: two fully adult, $11: 1: 11$, the outermost tooth missing; two young examples (diam. of shells $7 \mathrm{~mm}$.), $12: 1: 12$; the teeth increase in size from the centre to the tenth, which is the largest, the eleventh much smaller, and the last minute. In the adult specimens, I find here and there a central tooth scarcely more developed than the corresponding tooth in the young; the ten laterals on each side much exceed those of the young in size; but in the eleventh tooth there is no difference in size, the young one equals the adult; the growth of this tooth is arrested during the early life of the animal, and, like its outer neighbour, when present, has become functionless. 'T'o some extent this applies to the central tooth, and may account for its loss in some specimens.

The pedal gland opens below the month; it extends back in the body-cavity as a simple tube, with one or two small convolutions near the posterior end, and terminates in the substance of the foot. A small tunnel-like cavity extends from the point where the gland ends to almost the end of the tail; it does not open at the posterior end in a mucous pore; from the sides of this cavity proceed numerous small ducts; these are again divided, and extend to almost every part of the foot, supplying it with mucous.

Genitalia (Pl. XVII, Fig. 6). - Penis ( $p$.) with the retractor muscle (r.m.p.) at the apex; the prolongation, or epiphallus, (epi.) arises from the posterior third; between this point and the insertion of the retractor muscle, the penis appears folded upon itself, and the two parts welded together; the duct of the epiphallus enters the penis eavity at the apex, and the interior walls of both are studded with minute papillæ. An examination of several specimens proves a small amount of variation in the male organs, but none whatever on the female side (Figs. $6 a$ and $6 b$ are given in illustration of this). The epiphallus usually rests on the dorsal surface of the buccal mass, except when it takes the form shown in Fig. $6 b$. The ovotestis small and imbedded in the liver, hermaphrodite duct (h.d.) closely convoluted, albumen gland (al.g.) large. The spermatheca ( $s p r$.$) sub-cylindrical$ in its lower portion, thence a somewhat contracted and twisted upon itself, slightly enlarging above and closely adhering to the uterus.

The muscular arrangement is very simple: the tentacle and buccal mass retractors arise from the columellar muscle; the former, at about 
a third their length from the posterior end, divide into two bands, the smaller of which supply the inferior tentacles. The right tentacle retractor passes through the genital branch, with the inferior retractor on the left; the male organs thus pass through the loop formed by the two muscle bands.

The nervous system, in its position, is characteristic of this group of animals. The cerebral, pleural, and pedal ganglia with their commissures and connectives, form a ring round the anterior portion of the buccal mass; the buccal ganglia are situate close behind the entrance to the œsophagus; a buccal nerve on each side unites with the anterior ganglia, forming a small commissure encircling the œsophagus and salivary ducts. Compared with Natalina Caffra, Fér., there is no difference in the principal features, and Woodward's figures and description of the nervous system of that animal apply perfectly to $R$. Greenwoodi, Gray.

\section{Rhytida Meesoni, Suter. Pl. XVII, Fig. 7.}

Two examples of this species were examined, both unfortunately dead and dried up in the shells; however, I offer a brief note touching those features that were clearly distinguishable. The mantle has an even margin; there are two small lobes on the right side, corresponding in position with the right and sub-median lobes in the preceding species. The buccal mass has the form usual in this group of animals; the osophagus and two salivary ducts enter in the anterior third; the salivary glands appear to be quite distinct from each other. Suter has described and figured the dentition (Trans. New Zeal. Inst, vol. xxii, p. 84, pl. xvii, fig. f, A); he gives the formula $12: 0: 12$, the tenth tooth largest and with an angular rib, the eleventh less than half the size, and the twelfth minute. The radula before me has a central tooth with twelve laterals on each side; the elerenth tooth is the largest, and has an angular rib, the twelfth less than half its size; there is no indication of the minute outer tooth.

Genitalia (Pl. XVII, Fig. 7).-The penis ( $p$. ) sickle-shaped, with the retractor muscle (r.m.p.) at the posterior end; the vas-deferens ( $v . d$. enters about the middle. The spermatheca $(s p r$.$) separates from the$ oviduct about midway between the sacculated portion and the genital cloaca; it forms a slender tube adhering to the upper portion of the oviduct; its posterior extremity, also the albumen gland, ete., were lost in extracting the animals. The pedal gland, pedal cavity, and position of the nerve-collar are similar to those of $R$. Greenwoodi; also the right tentacle retractor passes through the genital branch.

\section{Rhenea Coresia, Gray. Pl. XVII, Figs. 1-4.}

The animal is whitish in colour, with narrow grey lines radiating to the foot-margin; tentacles darker; foot somewhat narrow, thrown into minute undulations when the animal is in motion; mantle slightly projecting over the peristome of the shell. The mouth or lips minutely crenulated; this allows of considerable distension, and pernits the odontophore to be much protruded. The animal is apparently ovoviviparous; a single embryonic shell (Pl. XVII, Fig. 1) was found 
when preparing the animal for dissection. The buccal mass (Pl. XVII, Fig. 3) is large and cylindrical, the posterior end curved down and forward; the salivary gland (s.g.) dark in colour, is composed of two lobes, but the cohesion of the two is so intimate that it may be considered a single median gland, with two ducts (s.d.) emptying into the buccal cavity. The dentition (Pl. XVII, Fig. 2) has the formula $9: 0: 9$; the teeth, disposed in numerous transverse rows which form an obtuse angle, are all aculeate, robust, and smooth, the second one being the largest, from this outward gradually getting smaller; the third equals the second in length, but less robust; the first about equals the fifth. The absence of a central tooth leaves a wide rhachidian eleft. The above description is slightly at variance with that published by Captain Hutton (Trans. New Zeal. Inst., vol. xvi, p. 172, pl. xi, fig. E).

Genitalia (Pl. XVII, Fig. 4) simple: penis $(p$. $)$ with the retractor muscle $(r . m . p$.$) at the posterior end, the vas-deferens (v . d$.$) enters$ a little below the apex, and forms a short slender tube. The spermatheca $(s p r$.$) is small and pear-shaped, resting on a short narrow neck; it is$ situate at the posterior end of the free tube of the oviduct (ovd.), and partly concealed by the adjoining sacculated portion. The right tentacle retractor passes on the left of the genital system. 'The pedal gland forms a minute tube; doubtless, the tunnel-like cavity in the tail occurs also, but, unfortunately, it was not investigated when dissecting the animal, and want of material prevents the question being settled for the present.

The nervous system, in its structure and position, is so similar to that of Rhytida that a description seems unnecessary.

\section{Schizoglossa Nuvoseelandica, Pfr. Pl. XVII, Figs. 8-10.}

The animal has been excellently described by Hedley (Proc. Linn. Soc. New South Wales, ser. II, vol. vii, pp. 387-392, pls. ix, x), and the alimentary and genital systems fully treated. There is little to add to the description of the external features, except to note the presence of two small labial tentacles. The mantle (Pl. XVII, Fig. 9) has an even margin, with two small lappets on the under side; the right (r.l.) proceeds forward from a little behind the respiratory pore (rs.p.), extends to almost a third of the length of the mantle margin, and forms a narrow fold; the left (l.l.) is minute, simply a rudiment, and in some specimens difficult to detect.

The points of attachment of the principal retractor muscles are of special interest. Hedley pointed out the remarkable little pit, excavated in the shell, for the reception of the shell, or columellar, muscle, and the writer noted a small elongated muscle-scar on the left side of the shell (Proc. Malac. Soc. Lond., Vol. i, p. 138). Fig. 8 of Pl XVII shows the position of these muscle-scars, as well as the thick callous rib, which in this example borders the scar on the columella.

Dissection of the animal (Pl. XVII, Fig. 10) reveals the following features:- The buccal mass retractor (b.m.r.) is inserted in the 
posterior margin of the diaphragm $(p . m . d$. ) a little to the right of the middle; it unites with the shell in the little pit excavated therein, and in part with the columella. The right tentacle retractor (r.t.r.) unites with the diaphragm, a little anterior to, and about one millimetre to the right of, the buccal mass retractor. The left tentacle retractor (l.t.r.) is inserted in the left maroin of the diaphragm, slightly anterior, and about three millimetres to the left of, the insertion of the buccal mass retractor; it corresponds in position with the narrow muscle-scar on the shell. The pedal muscles have degenerated, and much resemble those of the true slugs. I failed to discover any indication of a true columellar muscle; the strongly developed retractor of the buccal mass serves that purpose, and in its peculiar attachment with the shell doubtless receives the maximum of resistance.

The position of the organs viewed from above is as follows :Buccal mass large, the posterior half concealed by the salivary glands; the latter lie side by side, and are united by a few delicate threads. The genital system is on the right side, the large albumen gland above the retractor of the buccal mass, and immediately posterior to the salivary glands; the hermaphrodite duct proceeds to the left, its gland being imbedded in the liver. Removing the salivary and albumen glands, the small stomach is seen passing gradually towards the left side of the buccal mass, its posterior end enveloped by the liver and receiving the right and left hepatic ducts. The intestine passes through the folds of the liver; it is very short, little more than equalling the stomach in length, passes back to almost the posterior limit of the visceral cavity (the latter extends considerably behind the posterior margin of the diaphragm, as indicated by the dotted lines in Fig. 10), thence makes a small complete turn to the right, curving under the posterior end of the buccal mass retractor, then upward and to the right over the muscle, terminating in a short rectum. The lobes of the liver are about equal in size. The left tentacle retractor proceeds on the outer left side of all the organs; it has a slightly curved line of resistance, but much less so than if it were applied close to the pharangeal retractor; the latter and right retractor proceed side by side, the line of resistance being direct. The pedal gland ( $p d g$.) extends back to the position indicated in Fig. 10, where it ends in a slight enlargement. attached and lightly impressed in the substance of the foot. A small cavity proceeds from the posterior end of the visceral cavity, to almost the end of the tail, shorter, but otherwise similar to, those of Rhytida and of Paryphanta Hochstetteri, Pfr. In these animals, the large muscles proceeding from the foot to the columella are pierced by a small tunnel, which receives the posterior end of the pedal gland. The absence of these muscles and a slight excavation of the substance of the tail have provided for the reception of a considerable portion of the viscera, and thus separate the pedal gland from the cavity in the tail, the former remaining unchanged.

The nerve ganglia and their accompanying connectives are situated similarly to those of the preceding species.

I have examined the genitalia of sereral specimens, but failed to discover any trace of the spermatheca. 


\section{Paryphanta Hochstetteri, Pfr.}

The muscular and nervous systems are similar to those of Rhytida, as are also the pedal gland and cavity. Godwin-Austen has described its anatomy (Proc. Malac. Soc. Lond., Vol. i, pp. 5-9, Pl. i), so that further description seems hardly necessary. I may mention that the oviduct and penis do not unite to form a common vestibule; examined externally, both are seen in the same epidermal pore, but each organ with a distinctly separate orifice, a space of rather more than a millimetre separating them.

\section{Natalina Cafrra, Fér.}

A specimen has been dissected and compared with the several species previously noted; the example proves that the cæcum or appendicula of the oviduct forms a receptacle for the spermatophores. The latter (Pl. XVII, Fig. 11) is hard, almost leathery in substance, curved and tapering towards the ends; the anterior end is shortly curved inward, hollowed out and scoop-like; the outer surface is longitudinally ribbed, and in cross-section seen to be deeply cleft into segments. An accident deprived me of the foot before completing the examination, and I am unable to state whether it has a pedal cavity or not.

Its anatomy is in many respects similar to that of Rhytida and of Paryphanta; nevertheless, it offers a marked generic distinction in the peculiar type of its radula and the accessory organ on the oviduct. It differs also in that the right tentacle retractor passes to the left of the genital system; but it remains to be proved whether this position is constant in other species, and the same remark applies to Paryphanta. In sheil character it appears more nearly allied with Rhytida.

\section{COMPARISON OF THE FOREGOING GENERA.}

Rhytida and Paryphanta differ chiefly in the composition of the shell and shape of the foot; the former has a somewhat narrow foot and acutely pointed tail ; in the latter the foot is expanded and the tail ovate. In Paryphante the shell is clothed with a thick periostracum, and in certain species the apical whorls alone contain calcareous matter, the remainder consisting of conchin (Suter, Journ. Malac., vol. vii, 1899, pp. 49, 50). In Rhytida the shell contains more carbonate of lime, and is more brittle. The radula does not present a very decidedly marked difference.

Rhenea comprises two species differing much in the character of their shells: $R$. Coresia, Gray, in form and composition of shell is a miniature Paryphanta Busbyi, Gray, whereas Rhenea Jeffreysiana, Pfr., closely resembles a Flammulina. The latter appears to be a rare species, and I have not had an opportunity of examining its anatomy. Hutton has described the dentition (Trans. New Zeal. Inst., vol. xvi, p. 172 , pl. xi, fig. F), which in many respects resembles that of $R$. Coresia. Whether both species are ovoviviparous, yet remains to be determined. The narrow foot is more in accord with Rhytida, to which perhaps it 
stands nearest. I would suggest that its position is between Paryphanta and Rhytida, possessing certain of the features of each, but, in the sum-total, agreeing with neither.

Schisoglossa.-Hedley, in describing the genus, pointed out its position, and suggested Paryphanta as the nearest of kin. 'The correctness of this view seems to the writer abundantly proved. With P. Hochstetteri, Pfr., it agrees in the shape of the foot, the shallow grooves proceeding from the lips and extending around the footmargin ; it also exhibits a very similar dentition. The modified pedal cavity, the reduced lappets on the mantle, and the periostracal covering of the shell are, I submit, evidence of relationship. Suter states it is evidently a Paryphanta in which the shell has become vestigial, but he does not support the statement with any evidence. 'The peculiar muscular attachment with the shell suggests degeneration. The posterior position of the muscle attached to the columella would not of itself give to an auriform shell, that secure attachment necessary to an animal whose habitat is amidst a tangled decaying vegetation. The narrow muscle on the left side adds considerably to the security of the shell, and I regard it as the more recent development, due to a change in condition, a link in the evidence of degeneration from the more helicoid form to the existing slug-like animal. Compared with Testacella haliotidea, Drap., the difference is almost complete, the nervous system alone showing any near resemblance.

Nore. - Since writing the above paper Mr. M. F. Woodward has directed my attention to the hermaphrodite duct, and queries the presence of an appendix thereto.

A careful scrutiny proves that in Rhytida Greenwoodi there is an appendix; it is situated close to the albumen gland, is about $1.5 \mathrm{~mm}$. in length, and much resembles a convolution of the hermaphrodite duct. In Paryphanta Hochstetteri it does not occur, and I failed to find any trace of it in Schizoglossa Novoseelandica. An animal of the latter species contained within the sacculation of the uterus six fully developed eggs with calcareous shells. I may also mention that in several species of Flammulina there is an appendix to the hermaphrodite duct; it is imbedded in the albumen gland, and its minute apex is alone visible externally. 



\section{$2 \mathrm{BHL}$ Biodiversity Heritage Library}

Murdoch, R. 1901. "ON THE ANATOMY OF SOME AGNATHOUS MOLLUSCS FROM NEW ZEALAND." Proceedings of the Malacological Society of London 4, 166-173.

View This Item Online: https://www.biodiversitylibrary.org/item/53747

Permalink: https://www.biodiversitylibrary.org/partpdf/202770

\section{Holding Institution}

Smithsonian Libraries

\section{Sponsored by}

Smithsonian

\section{Copyright \& Reuse}

Copyright Status: Public domain. The BHL considers that this work is no longer under copyright protection.

This document was created from content at the Biodiversity Heritage Library, the world's largest open access digital library for biodiversity literature and archives. Visit BHL at https://www.biodiversitylibrary.org. 